\title{
Correction to: Evaluating preferences for colorectal cancer screening in individuals under age 50 using the Analytic Hierarchy Process
}

Travis Hyams ${ }^{1,2^{*}}$, Bruce Golden ${ }^{3}$, John Sammarco ${ }^{4}$, Shahnaz Sultan ${ }^{5}$, Evelyn King-Marshall ${ }^{1}$, Min Qi Wang ${ }^{1}$ and Barbara Curbow ${ }^{1}$

\section{Correction to: BMC Health Serv Res 21, 754 (2021)} https://doi.org/10.1186/s12913-021-06705-9

Following publication of the original article [1], some content was missing in Funding section. The updated Funding is given below and the missing content have been highlighted in bold typeface.

The original article [1] has been corrected.

\section{Funding}

No funding to declare. The opinions expressed by the authors are their own and this material should not be interpreted as representing the official viewpoint of the U.S. Department of Health and Human Services, the National Institutes of Health or the National Cancer Institute.

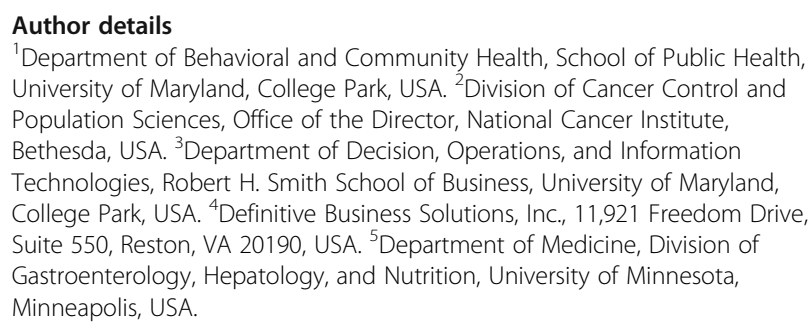

Published online: 29 September 2021

\section{Reference}

1. Hyams, et al. BMC Health Serv Res. 2021;21:754.

The original article can be found online at https://doi.org/10.1186/s12913021-06705-9.

*Correspondence: Thyams@umd.edu

'Department of Behavioral and Community Health, School of Public Health, University of Maryland, College Park, USA

${ }^{2}$ Division of Cancer Control and Population Sciences, Office of the Director, National Cancer Institute, Bethesda, USA long as it is attributed back to the author. Readers are permitted to alter, transform or build upon the Article, and to use the Article for commercial purposes. Please read the full license for further details at - http://creativecommons.org/licenses/by/4.0/. This license enables owners of copyright- or database-protected content to waive the rights they hold in their works and thereby dedicate them to the public domain, to the extent permitted by law, so that others may freely build upon, enhance and reuse the works for any purposes without restriction under copyright or database law. Please read the full license for further details at -https://creativecommons.org/share-your-work/public-domain/cc0/. 